\title{
Reflexões sobre a história em um tempo de crise
}

\author{
Reflections on history in a time of crisis
}

MALERBA, Jurandir (org.). Lições de história: da história científica à crítica da razão metódica no limiar do século XX. Rio de Janeiro: Editora FGV; Porto Alegre: Edipucrs, 2013, 539 p.

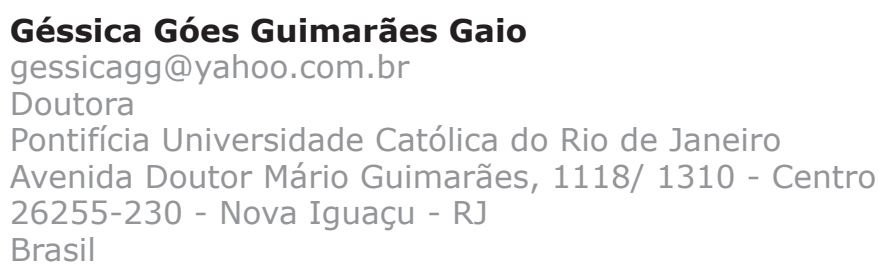

Palavras-chave

Historicismo; Historiografia moderna; Ciências humanas.

Keywords 
Em Lições de história o leitor encontrará bem mais do que uma cartilha sobre a disciplina: estará em suas mãos uma seleção de textos voltada para o público especializado (sobretudo graduandos e pós-graduandos em História ou demais ciências sociais) e cuja importância no cenário editorial brasileiro é inquestionável. Trata-se de um livro audacioso, que em suas mais de quinhentas páginas oferece traduções de textos, em sua maioria inéditos em língua portuguesa, precedidos por apresentações críticas elaboradas por destacados representantes dos estudos de Teoria da História e de História da Historiografia nas universidades e centros de pesquisa do Brasil.

Este volume figura como uma continuação do projeto anterior: Lições de história: o caminho da ciência no longo século XIX, publicado em 2010, também sob a organização de Jurandir Malerba - professor da PUCRS e primeiro ocupante da Cátedra Sérgio Buarque de Holanda de Estudos Brasileiros, na Freie Universität, em Berlim. Todavia, se na primeira empreitada interessava ao debate a constituição do caráter científico da história e sua institucionalização, notadamente a partir dos trabalhos de pensadores do Velho Mundo, tais como Voltaire, Jules Michelet, Leopold von Ranke, Thomas Macaulay, Fustel de Coulanges, Charles Seignobos, entre outros, a publicação aqui apresentada tem como ponto de partida a querela acerca das proximidades e afastamentos entre as "ciências naturais" e as "ciências humanas" na passagem do Oitocentos para o Novecentos. Para tal, são apresentados artigos, trechos de livros e fragmentos de dezessete intelectuais - entre eles se destacam em maior número os alemães - para os quais o estatuto científico da história é, no mínimo, alvo de reflexão.

Os textos e autores reunidos têm em comum a preocupação com as possibilidades e as consequências de se pensar a história como uma ciência, preocupação motivada pela crítica à razão (sobretudo a sua matriz iluminista), que, no limite do século XIX, se instalara como um mal-estar sobre historiadores e filósofos. O paradigma científico advindo da física e da matemática exigiria do observador objetividade e neutralidade na análise de seu tema de pesquisa. A imposição de ajustar-se a tais critérios de cientificidade levou alguns historiadores do século XIX a afirmarem a plena possibilidade de a história realizar uma investigação comprometida com a verdade e comprovada pelas fontes históricas. No último quartel desse século, no entanto, muitos pensadores apontavam para o valor da dúvida e conferiram notoriedade às discussões em torno do papel da subjetividade no estudo do passado.

Compartilhando esse cenário de incertezas, os intelectuais aqui reunidos empenharam-se em refletir sobre a especificidade do conhecimento produzido a partir da investigação dos tempos pretéritos. Se, por um lado, a história não apresentava os atributos de uma ciência da natureza, em outra medida seus partidários estavam certos de que o conhecimento adquirido pela averiguação e ponderação sobre os acontecimentos do passado tinha uma função central para o amadurecimento dos indivíduos e das sociedades. Sendo assim, os historiadores e filósofos aceitavam os limites impostos à pesquisa historiográfica, que incluíam a impossibilidade de estabelecer leis que explicassem o desenvolvimento da história. Em resposta, afirmavam que, embora historicamente condicionado, o conhecimento sobre o passado também possuía sua legitimidade. 
Compõem o quadro de interesse desse debate os seguintes questionamentos: qual seria o objeto de estudo da história e de que maneira a história se diferencia das ciências naturais; como deveríamos lidar com a subjetividade do historiador e como a pesquisa historiográfica poderia ser validada? Mas, provavelmente, o cerne dessa reflexão consista no "problema da historicidade", como sugeriu Allan Megill na eficiente e elucidativa Introdução aos textos e comentários. A percepção de que a relação entre o homem e o tempo é intrínseca à própria experiência da história, isto é, a concepção do homem como um ser no tempo e do tempo, instala uma crise no seio da historiografia, pois a tentativa de escrever a história como ela realmente aconteceu estava definitivamente ameaçada pela concepção de que o historiador enxerga o passado a partir de um ponto de vista.

Na esteira desse processo, a "grande narrativa" ou, em outras palavras, a concepção de uma história universal capaz de contemplar o devir de toda a humanidade, sofreu insistente descrédito em favor de uma história que privilegiasse não somente os grandes homens e feitos gloriosos, mas que lançasse luz sobre o cotidiano e as formas de pensar daqueles que viveram no passado. Portanto, a dúvida sobre o avanço da razão, preconizada pelos românticos no início do século XIX, encontrou no seio da discussão acerca da natureza da história o locus por excelência para a defesa da subjetividade. O historiador assumia assim o seu enraizamento histórico e, ao se apropriar de sua própria historicidade, conferia maior superfície ao passado estudado. 0 reconhecimento da subjetividade tornou o historiador mais sensível à sua tarefa

210 e possibilitou que instrumentos cognitivos como a compreensão e a imaginação se tornassem o cerne da produção historiográfica.

O diálogo proposto por esta seleção se iniciou temporalmente com Fado e história de Nietzsche, publicado em 1862, e se estendeu até os primeiros anos da Segunda Guerra com o texto Como e por que trabalha um historiador, de Marc Bloch. E, se os textos aqui traduzidos mantêm um tema em comum acerca da cientificidade da história e do papel do historiador na escrita sobre o passado - , a variedade de interpretações e as soluções propostas confirmam a necessidade de um olhar mais cuidadoso sobre esse debate.

Seguindo a proposta de análise da Introdução de Allan Megill, podemos perceber que nos textos de autoria de Wilhelm Dilthey, Karl Lamprecht, Wilhelm Windelband, Heinrich Rickert, Max Weber e Friedrich Meinecke a questão sobre o método e a concepção da antinomia entre as ciências naturais e as ciências humanas ocupam o centro das preocupações. A caracterização das ciências naturais como as ciências do "geral" e das ciências humanas como as ciências do "singular" não contempla as exigências teóricas desses intelectuais. Elejo como exemplo a exposição de Rickert em As quatro formas do "geral" em história.

Segundo Rickert, a história "[...] expõe a especificidade e a individualidade de uma dada coletividade histórica em um dado local e numa dada época e jamais procura constituir um sistema de conceitos gerais no qual isso está contido para todas as épocas e lugares" (RICKERT 2013, p. 195).

Embora as assertivas da historiografia não possuam caráter genérico capaz de produzir leis, como as da química, por exemplo, o intelectual alemão 
afirmou que, ainda assim, o conhecimento historiográfico poderia ser considerado científico, pois se relacionaria com quatro formas do "geral" responsáveis por conferir inteligibilidade ao objeto de estudo da história.

Sendo assim, e de acordo com Rickert, o estudo da individualidade se relacionaria com aquilo que é comum a um grupo de pessoas e deve levar em conta: os elementos anteriores ao estudo, como a linguagem; a seleção dos fatos estudados a partir de uma relevância que não deve ser idiossincrática, porém a expressão de um sentido para uma coletividade; que o próprio objeto histórico se encontraria inserido em um contexto no qual sua individualidade e o "mundo" se tocam; e, por fim, a elaboração de conceitos gerais, capazes de conferir sentido a uma realidade histórica estudada - tais como o de tipos ideais, de Max Weber.

A afirmação da cientificidade da história se fundamentava na certeza que Rickert divulgava como uma advertência:

[...] é particularmente estranha a crença em um único método científico universal precisamente entre os historiadores, o quais devem conhecer a diversidade do agir humano. O espírito humano é demasiado complexo, e igualmente complexa é sua atividade científica (RICKERT 2013, p. 199).

Ainda segundo Megill, em Jacob Burckhardt, Friedrich Nietzsche, Georg Simmel, Benedetto Croce e Robin George Collingwood destaca-se a crítica à grande narrativa. Em Fado e história, um Nietzsche de apenas 17 anos compreende o universalismo e a causalidade da grande narrativa como um fado que se opõe à vontade e à liberdade de ação do homem. Já nesse texto de juventude, o filósofo alemão invocava o debate sobre a moral e a responsabilidade ao relacionar essa lei da causalidade histórica a um achatamento da ação no mundo, pois "se esse fosse o único princípio, então o homem é uma bola de brinquedo de obscuras forças atuantes, irresponsável por seus erros, completamente livre de diferenciações morais, um elo necessário em uma cadeia" (NIETZSCHE 2013, p. 110). Podemos perceber aqui um diálogo com a tradição do idealismo alemão, de matriz nitidamente kantiana, e da qual Nietzsche se aproximou posteriormente, provavelmente a partir da leitura dos textos filosóficos de Schiller, sobretudo acerca da tragédia.

Por fim, um terceiro grupo seria formado pelos textos dos norte-americanos Charles Beard, Carl Becker e James Harvey Robinson e os franceses Marc Bloch, Lucien Febvre e Henri Berr, para os quais o historiador assume a dianteira da produção do conhecimento histórico. Assim como nos contam Edgard de Decca e Mauro de Decca, para Carl Becker, por exemplo, os fatos do passado somente seriam dotados de sentido a partir da experiência do presente e dos interesses em jogo no ato de inquirir os tempos pretéritos. Em outras palavras, na compreensão de Becker, o historiador busca no passado aquilo que importa a seu tempo.

Carl Becker - que figura como um representante da Nova História nos Estados Unidos ao lado de Beard e Robinson, todos sob a influência de F. J. Turner -, em uma de suas principais obras, The heavenly cities of the eighteenth-century philosophers, afirmara que, ao consolidar uma ideia da Idade Média 
como uma "idade de trevas", os filósofos ilustrados puderam construir a utopia do progresso que marcou seu tempo. Becker então concluiu que o domínio sobre o passado poderia ampliar as possibilidades de alcançar o futuro desejado.

O relativismo radical de sua análise se fundamentava na concepção de que a história é sempre reescrita e reinterpretada a partir dos novos projetos que o presente vislumbra. E o próprio historiador norte-americano recorreu a Benedetto Croce para enfatizar que toda história é contemporânea. Seu desejo de ampliar o debate acerca dos métodos da pesquisa historiográfica o motivou a proferir na American Historical Association, na qualidade de seu presidente, a palestra inaugural de 1931 intitulada O homem comum é seu próprio historiador, um discurso provocador sobre as possibilidades da narrativa sobre o passado, traduzido neste volume.

Esse cenário histórico que Jacob Burckhardt considerou como um momento de crise foi profundamente marcado pelo que muitos historiadores denominam a "crise do historicismo". Contudo, nessa denominação já reside um desafio: o significado da palavra "historicismo" está longe de encontrar um terreno pacífico. Mesmo em Lições de história encontramos diferentes conotações atribuídas ao termo, pois, se Oswaldo Giacoia Junior, no comentário ao texto de Nietzsche, fala de uma "versão como positivismo", na qual o historicismo "considera a história como celeiro de fatos e processos a ser ordenados em relações de causa e efeito" (GIACOIA JUNIOR 2013, p. 80); por sua vez, Luiz Sérgio Duarte da Silva aponta Karl Lamprecht como um historicista por verificar em seu pensamento um

212 afastamento em relação à tradição rankeana e prussiana, entendida como baluarte da história política e descritiva. Dessa maneira, se para Oswaldo Giacoia Junior a crise à qual se refere consiste na frustração da história teleológica, para Luiz Sérgio Duarte da Silva, "o problema fundamental do historicismo é o relativismo" (SILVA 2013, p. 133), que, na primeira década do século XX, colocava em xeque a neutralidade do historiador e a veracidade da pesquisa histórica.

Ora, acabamos de apontar duas "crises" deveras distintas. No primeiro caso, a tensão aponta para a superação do "historicismo" e a ruptura com uma historiografia de viés político que pleiteava a capacidade de desvendar os meandros do processo histórico. Já a segunda abordagem propõe um diálogo com essa tradição historicista, que não supõe superada, mas sim em constante transformação. Quando afirma que "o estado normal do historicismo é a crise" (SILVA 2013, p. 136), Luiz Sérgio Duarte da Silva nos permite pensar que talvez a assertiva que melhor traduziria a atitude historicista não seria "tudo é relativo", e sim "tudo é histórico". Mas de qualquer forma, parafraseando o subtítulo, nos deparamos com dois aspectos do mesmo cenário, quais sejam: os embates em torno da história científica e o fortalecimento da crítica da razão metódica no limiar do século $X X$.

\section{Referências bibliográficas}

BEISER, Frederick C. (ed.). The early political writings of the German romantics. Cambridge: Cambridge University Press, 1996. 
GIACOIA JUNIOR, Oswaldo. Nietzsche e a crítica do historicismo. In: MALERBA, Jurandir (org.). Lições de história: da história científica à crítica da razão metódica no limiar do século XX. Rio de Janeiro: Editora FGV; Porto Alegre: Edipucrs, 2013.

IGGERS, Georg. The German Conception of History. Estados Unidos: Wesleyan University Press, 1988.

KANT, Immanuel. Crítica da faculdade do juízo. Rio de Janeiro: Forense Universitária, 2005.

MALERBA, Jurandir (org.). Lições de história: da história científica à crítica da razão metódica no limiar do século XX. Rio de Janeiro: Editora FGV; Porto Alegre: Edipucrs, 2013.

MAN, Paul de. The Rhetoric of Romanticism. New York: Columbia University Press, 1984.

MEINECKE, Friedrich. El Historicismo y su Génesis. México: Fondo de Cultura Económica, 1982.

NIETZSCHE, Friedrich. O Nascimento da Tragédia ou Helenismo e Pessimismo. São Paulo: Companhia das Letras, 1992.

REILL, Peter Hans. The German Enlightenment and the Rise of Historicism. Los Angeles: University of California Press, 1975.

RICKERT, Heinrich. As quarto formas do "geral" em história. In: MALERBA, Jurandir (org.). Lições de história: da história científica à crítica da razão metódica nolimiar do século XX. Rio de Janeiro: Editora FGV; Porto Alegre: Edipucrs, 2013.

SCHILLER. Friedrich. Cartas sobre a educação estética da humanidade. São Paulo: Editora Herder, 1963.

. Teoria da Tragédia. São Paulo: Editora Herder, 1964.

SILVA, Luiz Sérgio Duarte da. Lamprecht: o historicismo em crise. In: MALERBA, Jurandir (org.). Lições de história: da história científica à crítica da razão metódica no limiar do século XX. Rio de Janeiro: Editora FGV; Porto Alegre: Edipucrs, 2013. 